\title{
Clinical implications of ribonucleotide reductase subunit M1 in patients with pancreatic cancer who undergo curative resection followed by adjuvant chemotherapy with gemcitabine
}

\author{
TORU AOYAMA ${ }^{1}$, YOHEI MIYAGI ${ }^{2}$, MASAAKI MURAKAWA ${ }^{1}$, KOICHIRO YAMAOKU $^{1}$, YOSUKE ATSUMI ${ }^{1}$, \\ MANABU SHIOZAWA ${ }^{1}$, MAKOTO UENO ${ }^{3}$, MANABU MORIMOTO ${ }^{3}$, TAKASHI OSHIMA ${ }^{4}$, NORIO YUKAWA ${ }^{4}$, \\ TAKAKI YOSHIKAWA ${ }^{4}$, YASUSHI RINO ${ }^{4}$, MUNETAKA MASUDA ${ }^{4}$ and SOICHIRO MORINAGA ${ }^{1}$ \\ ${ }^{1}$ Department of Gastrointestinal Surgery, Kanagawa Cancer Center; ${ }^{2}$ Molecular Pathology and Genetics Division, Kanagawa \\ Cancer Center Research Institute; ${ }^{3}$ Department of Hepatobiliary Pancreatic Oncology, Kanagawa Cancer Center, Yokohama, \\ Kanagawa 241-8515; ${ }^{4}$ Department of Surgery, Yokohama City University, Yokohama, Kanagawa 236-0004, Japan
}

Received August 25, 2015; Accepted February 7, 2017

DOI: $10.3892 / 01.2017 .5935$

\begin{abstract}
To the best of our knowledge, the clinical implications of using ribonucleoside reductase subunit M1 (RRM1) in patients who undergo curative resection and adjuvant chemotherapy have not been established. In the present study, the clinical data from 101 consecutive patients who underwent macroscopically curative resection, and who received adjuvant gemcitabine chemotherapy for pancreatic cancer at the Kanagawa Cancer Centre (Yokohama, Kanagawa, Japan) between April 2005 and December 2014 were retrospectively analyzed. The association between the RRM1 status and survival and clinicopathological features were assessed. Of the 101 patients, 41 patients expressed high levels of RRM1 expression $(40.6 \%)$. Although a significant difference was observed in lymphatic invasion, there was no difference between the two groups with regard to any other clinicopathological parameters. The median follow-up period was 67.3 months. There was a significant difference between the recurrence-free survival (RFS) rates at 5 years after surgery, which were 12.9 and $0 \%$ in the high RRM1 and low RRM1 groups, respectively $(\mathrm{P}=0.042)$. Furthermore, there was a significant difference in the 5-year overall survival (OS) rates following surgery, which were 5.1 and $21.5 \%$ in the high RRM1 and low RRM1 groups, respectively $(\mathrm{P}=0.015)$. The results of the present study indicated that out of the factors assessed, RRM1 was the most important prognostic factor for OS and RFS in patients with pancreatic cancer who underwent curative resection followed by adjuvant chemotherapy with gemcitabine. Adjuvant
\end{abstract}

Correspondence to: Dr Toru Aoyama, Department of Gastrointestinal Surgery, Kanagawa Cancer Center, 2-3-2 Nakao, Asahi-ku, Yokohama, Kanagawa 241-8515, Japan

E-mail: aoyamat@kcch.jp

Key words: pancreatic cancer, ribonucleoside reductase subunit M1, adjuvant chemotherapy, gemcitabine chemotherapy with gemcitabine alone may be insufficient for the treatment of pancreatic cancer, particularly in patients with relevant risk factors.

\section{Introduction}

Pancreatic cancer, which has a 5-year patient survival rate of $<5 \%$, is a major cause of cancer-associated mortality worldwide $(1,2)$. Complete resection is an essential part of treatment for patients with pancreatic cancer. However, only $10-20 \%$ of patients are candidates for curative resection. Furthermore, due to the high rate of recurrence, the postoperative 5-year survival rate is $15-25 \%$ when curative resection is performed (3-5). Several studies have conducted randomized controlled studies on adjuvant chemotherapy following pancreatic cancer resection (6-8). The European Study Group for Pancreatic Cancer 1 and 3 trials, and the Charite Onkologic 001 trial demonstrated that the administration of gemcitabine or fluorouracil plus folinic acid significantly improves overall survival following surgical resection in patients with pancreatic cancer in comparison to surgery alone (6-8). Based on these results, adjuvant chemotherapy with gemcitabine is now considered to be the standard treatment and is routinely recommended following curative resection for pancreatic cancer. However, adjuvant chemotherapy with gemcitabine is unable to completely prevent the development of recurrence. The selection of patients who would benefit most from gemcitabine treatment may be an important step towards improving the clinical outcomes associated with pancreatic cancer.

Ribonucleotide reductase subunit M1 (RRM1) is a multimeric enzyme that converts ribonucleotides to deoxyribonucleosides, both of which are required for DNA polymerization and repair $(9,10)$. It has previously been reported that the overexpression of the RRM1 gene is associated with gemcitabine resistance. Patients with advanced pancreatic carcinoma who exhibited high levels of RRM1 expression were demonstrated to have poor survival rates following gemcitabine treatment, while patients with non-small cell lung cancer who had low levels of RRM1 
expression were revealed to benefit significantly from gemcitabine/cisplatin neoadjuvant chemotherapy $(11,12)$. However, few published studies have evaluated the prognostic value of RRM1 expression in patients with pancreatic cancer who undergo resection followed by adjuvant chemotherapy with gemcitabine, and no definite conclusions have been made regarding the prognostic value of RRM1 in such patients $(13,14)$. Using cancer tissue samples from individuals, the characterization of the genes that are associated with tumor sensitivity or resistance and antitumor agents serves an essential role in the development and provision of individualized adjuvant chemotherapy treatments.

In the present study, RRM1 expression was investigated in consecutive patients who underwent curative resection followed by adjuvant chemotherapy with gemcitabine. In addition, the association between RRM1 expression and the clinicopathological parameters and survival rates of patients were evaluated.

\section{Patients and methods}

Patients. Consecutive patients were selected from the medical records of those who underwent pancreatic surgery at the Kanagawa Cancer Centre (Yokohama, Kanagawa, Japan) between April 2005 and December 2014. The following inclusion criteria were applied: i) A pathologically common type of pancreatic adenocarcinoma according to the definitions of the International Union Against Cancer (UICC) tumor-node-metastasis (TNM) 6th edition (15); ii) the patient had initially undergone curative resection, with the resected specimen available from the archive; and iii) the patient had received adjuvant chemotherapy with gemcitabine. The resected specimens were histopathologically examined and were staged according to the UICC TNM 6th edition (15). Patients with other pancreatic and periampullary neoplasms, including intraductal papillary mucinous neoplasm, cystadenocarcinoma and endocrine tumors, and patients who had undergone $\mathrm{R} 2$ resection were excluded from the present study. The present study was approved by the Institutional Review Board Committee of the Kanagawa Cancer Center.

Surgical procedure. All pancreatic surgeries were performed in accordance with standardized procedures that have been previously described (16-19). Briefly, for distal pancreatectomy cases, lymph node dissection was performed in the region of the celiac trunk, and the superior mesenteric artery and vein, in addition to behind the pancreas along the left side of the renal vein and the left adrenal gland. In each case, intraperitoneal drains were placed close to the pancreatic anastomosis and stump. For pancreaticoduodenectomy cases, pylorus-preserving pancreaticoduodenectomy was performed as the standard procedure. Lymph node dissection along the hepatoduodenal ligament, common hepatic artery, vena cava, superior mesenteric vein and the right side of the superior mesenteric artery was performed as part of the standard procedure. Multiple intraperitoneal drains were placed, with the first being posterior to the hepaticojejunostomy and the second on the anterior surface of the pancreaticojejunostomy or the closed remnant of the pancreas.
Adjuvant chemotherapy. Gemcitabine treatment was initiated within 8 weeks of surgery. The patients received a weekly dose via intravenously of $1,000 \mathrm{mg} / \mathrm{m}^{2}$ for 3 weeks, followed by 1 week of rest. Gemcitabine treatment was continued for 6 months.

Follow-up. Patients were followed up at outpatient clinics. Hematological tests and physical examinations were performed at least every 2 weeks during adjuvant chemotherapy treatment, and at least every 3 months for 5 years following the end of the adjuvant chemotherapy course. The carcinoembryonic antigen and cancer antigen 19-9 tumor marker levels were measured at least every 3 months for 5 years. Patients underwent a computed tomography examination every 3 months during the first 3 years after surgery, and then every 6 months until 5 years after surgery. Peritoneal recurrence was defined as positive when imaging results revealed at least one of the following findings: Massive ascites, ascites confirmed by cytology, enhanced abdominal nodules, abnormal intestinal wall thickness, increased fat density of the intestinal mesentery, diffuse hydronephrosis or an intraabdominal mass. Imaging results were assessed by a radiologist and two staff physicians at Kanagawa Cancer Center (Kanagawa, Japan). When liver metastasis was suspected based on the imaging results, gadolinium-ethoxybenzyl-diethylentriaminepenta-acetate-enhanced magnetic resonance imaging or contrast-enhanced ultrasonography was performed to confirm the diagnosis.

Immunohistochemical analysis of RRM1 expression. Hematoxylin and eosin-stained 5- $\mu \mathrm{m}$ slides containing specimens from each pancreatic adenocarcinoma sample were reviewed, and a representative tumor region and the corresponding formalin-fixed paraffin-embedded tissue block was selected for use in a tissue microarray. RRM1 expression was evaluated using human mouse monoclonal antibody directed against RRM1 (dilution, 1:100; \#60073-2; Proteintech Group, Inc., Chicago, IL, USA) and the horseradish peroxidase secondary antibody was Histofine ${ }^{\circledR}$ Simple Stain MAX-PO (\#424151; Nichirei Biosciences, Inc., Tsukiji, Japan). The immunohistochemical staining procedure was performed as described previously $(14,20)$. Images were captured using light microscopy. The intensity of the RRM1 staining was scored as follows: Grade 0, unstained; grade 1, slightly stained; grade 2, weakly stained in comparison to plasma and stroma cells; and grade 3, stained as strongly as plasma and stroma cells. For the evaluation of intratumoral RRM1 expression, if grade 2 or 3 staining was observed in $>50 \%$ of the neoplasm, the sample was considered to have high RRM1 expression, whereas if grade 0 or 1 staining was observed in $>50 \%$ of tumor cells, the sample was considered to have low RRM1 expression (Fig. 1). The cut-off value used was determined on the basis of previous study results $(14,20)$. The immunohistochemical evaluation of RRM1 expression was confirmed independently by two observers and a consensus was reached by joint review.

Statistical analysis. The significance of the correlations between RRM1 expression and clinicopathological parameters was determined using Fisher's exact or $\chi^{2}$ tests. Overall survival (OS) rate was defined as the period between surgery and 
Table I. Association between the clinicopathological characteristics of patients with pancreatic cancer and high ( $\mathrm{n}=41$ ) or low $(\mathrm{n}=60)$ ribonucleotide reductase $\mathrm{M} 1$.

\begin{tabular}{|c|c|c|c|}
\hline $\begin{array}{l}\text { Clinicopathological } \\
\text { characteristic }\end{array}$ & $\begin{array}{l}\text { Low RRM1 } \\
\text { group, n }(\%)\end{array}$ & $\begin{array}{l}\text { High RRM1 } \\
\text { group, n }(\%)\end{array}$ & P-value \\
\hline Gender & & & 0.725 \\
\hline Male & $33(55.0)$ & $24(58.5)$ & \\
\hline Female & $27(45.0)$ & $17(41.5)$ & \\
\hline Age, years & & & 0.955 \\
\hline$<65$ & $26(43.3)$ & $18(43.9)$ & \\
\hline$\geq 65$ & $34(56.7)$ & $23(56.1)$ & \\
\hline R status & & & 0.404 \\
\hline R0 & $52(86.7)$ & $33(80.5)$ & \\
\hline R1 & $8(13.3)$ & $8(19.5)$ & \\
\hline Tumor location & & & 0.233 \\
\hline Head & $46(76.7)$ & $27(65.9)$ & \\
\hline Body/tail & $14(23.3)$ & $14(34.1)$ & \\
\hline Pathological differentiation & & & 0.154 \\
\hline Well & $52(86.7)$ & $31(75.6)$ & \\
\hline Moderate/poor & $8(13.3)$ & $10(24.4)$ & \\
\hline UICC pT factor & & & 0.142 \\
\hline $\mathrm{T} 1 / \mathrm{T} 2$ & $6(10.0)$ & $1(2.4)$ & \\
\hline $\mathrm{T} 3$ & $54(90.0)$ & $40(97.6)$ & \\
\hline Lymph node metastasis & & & 0.259 \\
\hline N0 & $16(26.7)$ & $7(17.1)$ & \\
\hline N1 & $44(73.3)$ & $34(82.9)$ & \\
\hline Lymphatic invasion & & & 0.021 \\
\hline No & $33(55.0)$ & $13(31.7)$ & \\
\hline Yes & $27(45.0)$ & $28(68.3)$ & \\
\hline Vascular invasion & & & 0.551 \\
\hline No & $24(40.0)$ & $14(34.1)$ & \\
\hline Yes & $36(60.0)$ & $27(65.9)$ & \\
\hline
\end{tabular}

RRM1, ribonucleotide reductase subunit M1; UICC, International Union Against Cancer; pT, pathological T factor, tumor factor.

mortality. Recurrence-free survival (RFS) was defined as the period between surgery and recurrence or mortality. The data of the patients who had not experienced an event were censored at the date of the final observation. The OS and RFS rates were evaluated using univariate and multivariate analyses. OS and RFS curves were calculated using the Kaplan-Meier estimator method and compared using the log-rank test. The univariate and multivariate survival analyses were performed using Cox's proportional hazards model. $\mathrm{P}<0.05$ was considered to indicate a statistically significant difference. The survival data were obtained from hospital records or from the city registry system. All statistical analyses were performed using SPSS software (version 11.0; SPSS, Inc., Chicago, IL, USA).

\section{Results}

Patients. A total of 201 patients underwent surgical resection between April 2005 and December 2014. Of these patients,
101 were eligible for inclusion in the present study. The patients were aged between 40 and 78 years (median, 66 years), with 57 men and 44 women. In total, 28 patients underwent distal pancreatomy, 70 underwent pancreaticoduodenectomy and 3 underwent total pancreatic resection. The median follow-up period was 67.3 months (range, 22.2-122.7 months).

Association between clinicopathological factors and RRMI expression. High RRM1 expression was observed in 41 $(40.6 \%)$ patients (Table I). The clinicopathological factors were compared between patients with high and low RRM1 expression. In total, 9 clinicopathological factors were evaluated. The incidence of lymphatic invasion was significantly higher in the patients with high RRM1 expression compared with that in the low RRM1 expression group ( $\mathrm{P}=0.021$; Table I).

Survival analysis. The OS rates at 3 and 5 years post-surgery in the patients with high RRM1 expression were 10.5 and 


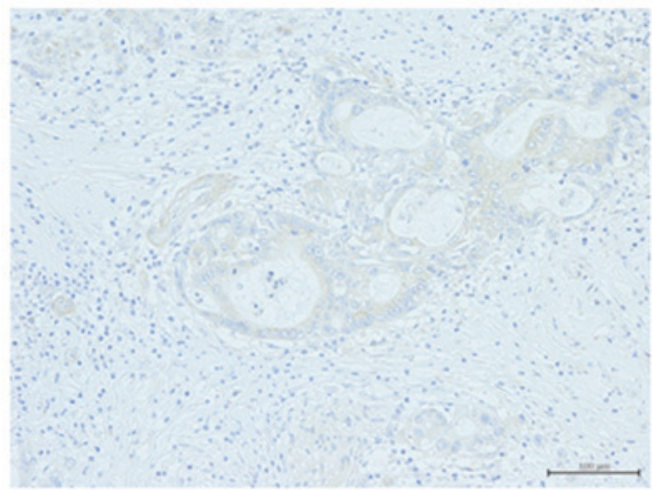

Immunohistochemistry scoring 0

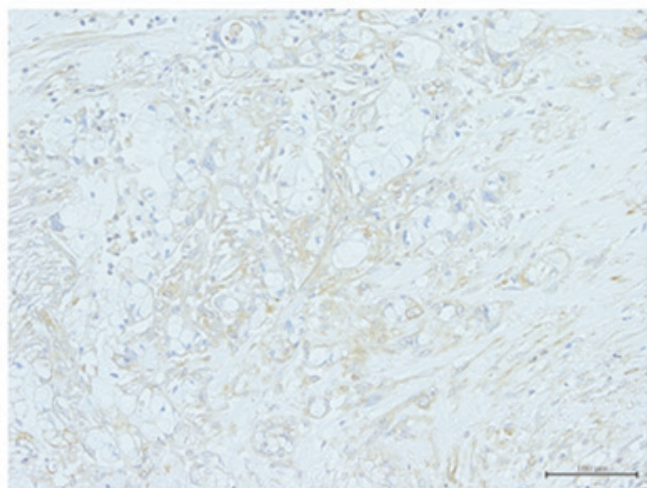

Immunohistochemistry scoring $1+$

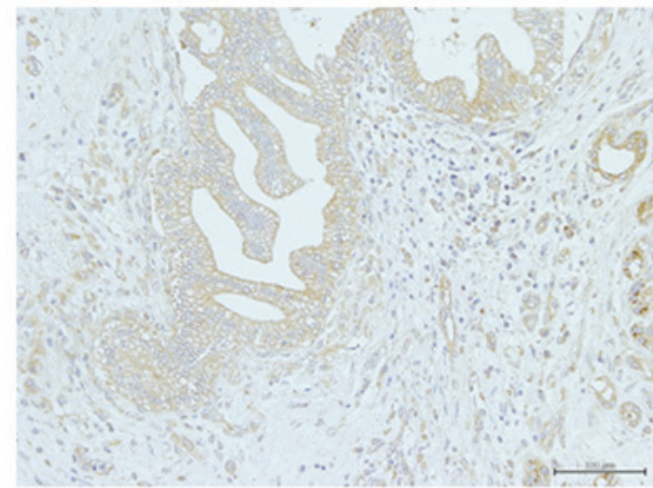

Immunohistochemistry scoring $2+$

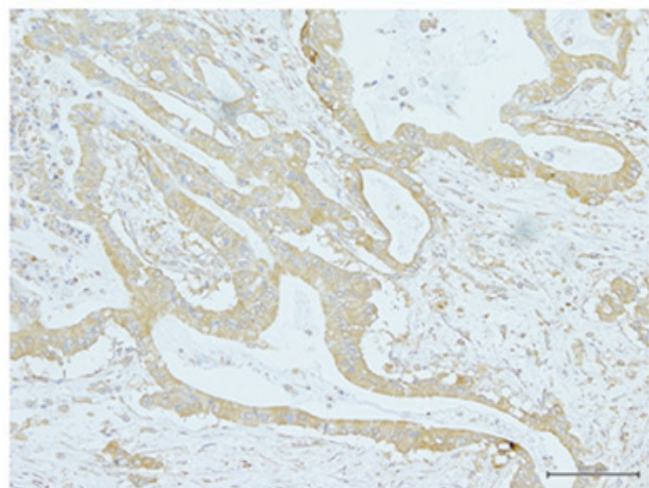

Immunohistochemistry scoring 3+

Figure 1. Representative results of the immunohistochemical staining of ribonucleotide reductase M1 in tissue samples from patients with pancreatic cancer (scale bar, $100 \mu \mathrm{m}$ ).

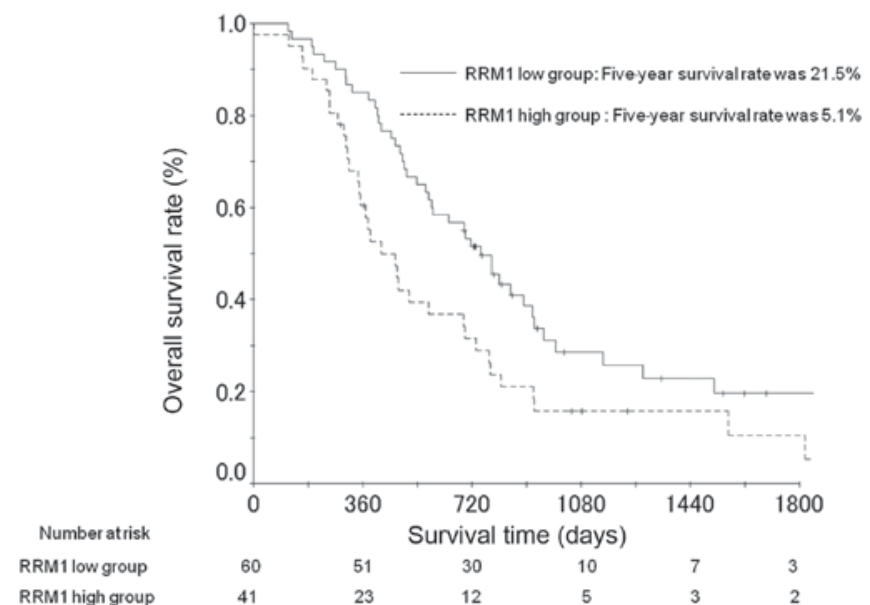

Figure 2. A comparison of the overall survival in the high and low RRM1 groups of patients with pancreatic cancer. The data below the graph represents the overall survival rate patients during the indicated time. RRMI, ribonucleotide reductase $\mathrm{M} 1$.

$5.1 \%$, respectively; and 25.7 and $21.5 \%$ in the patients with low RRM1 expression (Fig. 2). The difference between OS rates for patients with high and low RRM1 expression was identified to be significant following multivariate analysis $(\mathrm{P}=0.015$; Table II). Multivariate analysis also demonstrated that tumor location and lymphatic invasion were significant risk factors for OS (Table II).
The RFS rates at 3 and 5 years post-surgery in the patients with high RRM1 expression were 7.8 and $0 \%$, respectively (Fig. 3). For patients with low RRM1 expression, the RFS rates were 20.7 and $12.9 \%$, respectively (Fig. 3). The difference between RFS rates for patients with low and high expression was significant $(\mathrm{P}=0.042$; Table III). Multivariate analysis also demonstrated that tumor location, lymphatic invasion and resection status were significant risk factors for RFS (Table III).

\section{Discussion}

The present study evaluated the RRM1 status in patients with pancreatic adenocarcinoma who underwent curative resection followed by adjuvant chemotherapy with gemcitabine, and found that $40 \%$ of these patients exhibited high RRM1 expression. Furthermore, the OS and RFS rates of the patients differed significantly based on their RRM1 status. These results suggest that gemcitabine alone was insufficient as an adjuvant therapy, particularly in the patients with high RRM1 expression. Thus, these patients should be a target group for future clinical trials using novel treatments for pancreatic cancer.

Numerous studies have examined the presence and effect of RRM1 protein overexpression or gene amplification in patients with pancreatic adenocarcinoma. These studies reported that RRM1 is highly expressed in $20.4-87.3 \%$ of patients $(13,14,20-22)$. However, the measurement of RRM1 
Table II. Univariate and multivariate analyses of risk factors for the overall survival of patients with pancreatic cancer.

\begin{tabular}{|c|c|c|c|c|c|c|c|}
\hline \multirow[b]{2}{*}{ Factor } & \multirow[b]{2}{*}{$\mathrm{n}$} & \multicolumn{3}{|c|}{ Univariate analysis } & \multicolumn{3}{|c|}{ Multivariate analysis } \\
\hline & & OR & $95 \% \mathrm{CI}$ & P-value & OR & $95 \% \mathrm{CI}$ & P-value \\
\hline Gender & & & & 0.561 & & & 0.900 \\
\hline Female & 44 & 1.000 & & & 1.000 & & \\
\hline Male & 57 & 1.143 & $0.728-1.795$ & & 1.033 & $0.620-1.724$ & \\
\hline Age, years & & & & 0.740 & & & 0.626 \\
\hline$<65$ & 44 & 1.000 & & & 1.000 & & \\
\hline$\geq 65$ & 57 & 1.081 & $0.683-1.709$ & & 1.123 & 0.703-1.794 & \\
\hline $\mathrm{R}$ status & & & & 0.041 & & & 0.197 \\
\hline R0 & 85 & 1.000 & & & 1.000 & & \\
\hline $\mathrm{R} 1$ & 16 & 1.850 & $1.026-3.336$ & & 1.555 & $0.795-3.041$ & \\
\hline Tumor location & & & & 0.024 & & & 0.013 \\
\hline Body/tail & 28 & 1.000 & & & 1.000 & & \\
\hline Head & 73 & 1.840 & $1.085-3.120$ & & 1.980 & $1.153-3.400$ & \\
\hline $\begin{array}{l}\text { Pathological } \\
\text { differentiation }\end{array}$ & & & & 0.892 & & & 0.932 \\
\hline Well & 83 & 1.000 & & & 1.000 & & \\
\hline Moderate/poor & 18 & 1.042 & $0.572-1.898$ & & 1.029 & $0.533-1.988$ & \\
\hline UICC pT factor & & & & 0.035 & & & 0.273 \\
\hline $\mathrm{T} 1 / \mathrm{T} 2$ & 7 & 1.000 & & & 1.000 & & \\
\hline $\mathrm{T} 3$ & 94 & 4.545 & $1.113-18.559$ & & 2.284 & $0.522-9.997$ & \\
\hline $\begin{array}{l}\text { Lymph node } \\
\text { metastasis }\end{array}$ & & & & 0.038 & & & 0.704 \\
\hline No & 23 & 1.000 & & & 1.000 & & \\
\hline N1 & 78 & 1.802 & $1.034-3.140$ & & 1.131 & $0.599-2.136$ & \\
\hline Lymphatic invasion & & & & 0.001 & & & 0.009 \\
\hline No & 46 & 1.000 & & & 1.000 & & \\
\hline Yes & 55 & 2.192 & $1.374-3.498$ & & 1.898 & $1.174-3.066$ & \\
\hline Vascular invasion & & & & 0.032 & & & 0.283 \\
\hline No & 38 & 1.000 & & & 1.000 & & \\
\hline Yes & 63 & 1.678 & $1.044-2.695$ & & 1.358 & $0.776-2.377$ & \\
\hline RRM1 status & & & & 0.009 & & & 0.015 \\
\hline Low & 60 & 1.000 & & & 1.000 & & \\
\hline High & 41 & 1.814 & $1.160-2.837$ & & 1.777 & $1.116-2.830$ & \\
\hline
\end{tabular}

RRM1, ribonucleotide reductase subunit M1; UICC, International Union Against Cancer; pT, pathological tumor; CI, confidence interval; OR, odds ratio.

expression was not standardized and the background of the patients with pancreatic cancer was heterogeneous, as it included patients with stage I-IV tumors. Nakagawa et al (14) evaluated the incidence of RRM1 in resectable pancreatic cancer cases using immunohistochemical methods in 109 Japanese patients with pancreatic carcinoma who were treated with adjuvant gemcitabine-based chemotherapy following operative resection. It was demonstrated that RRM1 expression was observed in $44(40.4 \%)$ patients. In addition, Xie et al (22) measured RRM1 expression using reverse transcriptase-quantitative polymerase chain reaction analysis in 122 patients with resectable pancreatic adenocarcinoma. It was revealed that high RRM1 expression was observed in 44 (36.1\%) patients. These results were similar to the results of the present study. Thus, the incidence of high RRM1 expression is $\sim 40 \%$ in patients with resectable pancreatic cancer.

Regarding the association between RRM1 expression and clinicopathological factors, Akita et al (23) reported that in an analysis of 64 patients with resected pancreatic carcinoma, there were no significant differences in clinicopathological factors, including UICC pT factor, and lymph node status, between patients with high and low RRM1 expression. Nakagawa et al (14) reported similar results. In the current study, a significant difference was only observed in lymphatic 
Table III. Univariate and multivariate analyses of risk factors for the recurrence-free survival of patients with pancreatic cancer.

\begin{tabular}{|c|c|c|c|c|c|c|c|}
\hline \multirow[b]{2}{*}{ Factor } & \multirow[b]{2}{*}{$\mathrm{n}$} & \multicolumn{3}{|c|}{ Univariate analysis } & \multicolumn{3}{|c|}{ Multivariate analysis } \\
\hline & & OR & $95 \% \mathrm{CI}$ & P-value & OR & $95 \% \mathrm{CI}$ & P-value \\
\hline Gender & & & & 0.874 & & & 0.380 \\
\hline Female & 44 & 1.000 & & & 1.000 & & \\
\hline Male & 57 & 1.035 & $0.674-1.590$ & & 1.239 & $0.768-1.997$ & \\
\hline Age, years & & & & 0.293 & & & 0.272 \\
\hline$<65$ & 44 & 1.000 & & & 1.000 & & \\
\hline$\geq 65$ & 57 & 1.264 & $0.817-1.954$ & & 1.294 & $0.817-2.048$ & \\
\hline R status & & & & 0.001 & & & 0.007 \\
\hline R0 & 85 & 1.000 & & & 1.000 & & \\
\hline R1 & 16 & 2.668 & $1.469-4.845$ & & 2.322 & $1.261-4.276$ & \\
\hline Tumor location & & & & 0.016 & & & 0.014 \\
\hline Body/tail & 28 & 1.000 & & & 1.000 & & \\
\hline Head & 73 & 1.816 & $1.118-2.949$ & & 1.850 & $1.132-3.025$ & \\
\hline $\begin{array}{l}\text { Pathological } \\
\text { differentiation }\end{array}$ & & & & 0.775 & & & 0.747 \\
\hline Well & 83 & 1.000 & & & 1.000 & & \\
\hline Moderate/poor & 18 & 1.083 & $0.627-1.869$ & & 1.099 & $0.620-1.946$ & \\
\hline UICC pT factor & & & & 0.148 & & & 0.730 \\
\hline $\mathrm{T} 1 / \mathrm{T} 2$ & 7 & 1.000 & & & 1.000 & & \\
\hline $\mathrm{T} 3$ & 94 & 1.778 & $0.814-3.883$ & & 1.167 & $0.484-2.812$ & \\
\hline $\begin{array}{l}\text { Lymph node } \\
\text { metastasis }\end{array}$ & & & & 0.074 & & & 0.715 \\
\hline N0 & 23 & 1.000 & & & 1.000 & & \\
\hline N1 & 78 & 1.597 & $0.956-2.669$ & & 1.122 & $0.606-2.075$ & \\
\hline Lymphatic invasion & & & & 0.001 & & & 0.031 \\
\hline No & 46 & 1.000 & & & 1.000 & & \\
\hline Yes & 55 & 2.238 & $1.438-3.482$ & & 1.704 & $1.049-2.767$ & \\
\hline Vascular invasion & & & & 0.204 & & & 0.818 \\
\hline No & 38 & 1.000 & & & 1.000 & & \\
\hline Yes & 63 & 1.330 & $0.856-2.065$ & & 1.066 & $0.618-1.838$ & \\
\hline RRM1 status & & & & 0.008 & & & 0.042 \\
\hline Low & 60 & 1.000 & & & 1.000 & & \\
\hline High & 41 & 1.784 & $1.164-2.735$ & & 1.610 & $1.017-2.549$ & \\
\hline
\end{tabular}

RRM1, ribonucleotide reductase subunit M1; UICC, International Union Against Cancer; pT, pathological tumor; CI, confidence interval; OR, odds ratio.

invasion. However, there was no difference between the two groups in any of the other clinicopathological parameters of the patients with high and low RRM1 expression, including UICC pT factor and lymph node status. Thus, RRM1 expression appears to be independent from the other clinicopathological factors.

In the present study, the OS and RFS rates differed significantly based on the patients' RRM1 status. It is hypothesized that RRM1 is an essential enzyme that encodes the regulatory subunit of ribonucleotide reductase and catalyzes the reduction of ribonucleoside diphosphates to the corresponding deoxyribonucleotides for use in de novo DNA synthesis $(24,25)$.
There is a good rationale for this as gemcitabine is converted into gemcitabine diphosphate, an active metabolite capable of inhibiting ribonucleoside reductase, and RRM1 has been demonstrated to be a determinant of gemcitabine resistance in pancreatic cancer cells under in vitro conditions (11). Nakagawa et al (14) evaluated 109 patients with resected pancreatic cancer who underwent adjuvant chemotherapy with gemcitabine and were divided into 2 groups based on their RRM1 levels. A significant association was identified between disease-free survival and RRM1 expression $(\mathrm{P}=0.009)$. Furthermore, the patients with high RRM1 levels experienced poorer overall survival following gemcitabine treatment 


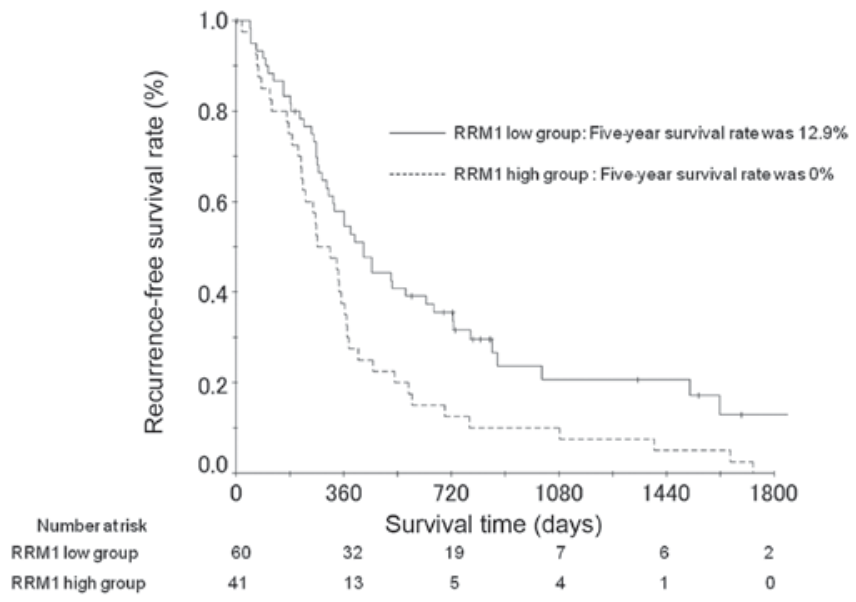

Figure 3. A comparison of the recurrence free survival in the high and low RRM1 groups of patients with pancreatic cancer. The data below the graph represents the recurrence-free survival rate of patients during the indicated time. RRMI, ribonucleotide reductase M1.

compared with those with low RRM1 levels $(\mathrm{P}=0.019)$. In addition, Akita et al (23) reported that patients with low RRM1 expression experienced significantly improved OS rate compared with patients with high RRM1 expression in an analysis of 68 patients with pancreatic carcinoma who underwent resection and received gemcitabine chemotherapy. A similar result was observed in a study of patients with advanced pancreatic cancer (11). Nakahira et al (11) evaluated 18 patients with recurrent pancreatic cancer who were treated with gemcitabine and who were divided into 2 groups based on RRM1 levels. A significant association was observed between gemcitabine response and RRM1 expression $(\mathrm{P}=0.018)$. Additionally, patients with high RRM1 levels exhibited poorer survival times following gemcitabine treatment compared with those patients with low RRM1 levels $(\mathrm{P}=0.016)$. The median survival time following gemcitabine treatment was 6.0 months in the patients with high RRM1 levels, while it was 14.6 months in the patients with low RRM1 levels. However, Giovannetti et al (26) demonstrated that there was no correlation between RRM1 expression and the clinical outcome of patients with pancreatic cancer. These controversial findings are probably associated with a range of factors, including the interaction with other genes, environmental effects on gene expression and differences in the detection methods, sample sizes and study design.

Particular attention is required when interpreting the results of the current study as there are several associated potential limitations. Firstly, the present study was a retrospective analysis and was performed at a single institution. Thus, the possibility that these findings were observed by chance cannot be excluded. Secondly, there was a selection bias in the patients in this series. Surgeons often avoid performing pancreatomy in certain patients, as the procedure is associated with high rates of morbidity (40-60\%) and mortality $(1-1.5 \%)(27-31)$. Thus, the fact that certain patients in this study received pancreatectomy could be considered a potential bias. In addition, the hospital is a specialized cancer center. Finally, the evaluation of RRM1 expression was not standardized. The appropriate RRM1 cutoff value remains unclear.
Considering these limitations, the results must be confirmed in another cohort or in a prospective multicenter-study.

In conclusion, the OS and RFS rates of patients with pancreatic cancer who underwent curative resection followed by adjuvant chemotherapy with gemcitabine differed significantly based on their RRM1 expression. These results suggest that gemcitabine was insufficient, particularly for the patients with high RRM1 expression. Thus, these patients should be a target group for future clinical trials using novel treatments for pancreatic cancer.

\section{Acknowledgements}

The present study was supported by the Kanagawa Prefectural Hospitals Cancer Fund (grant no., KCCH26-2), the Yokohama Foundation for Advancement of Medical Science and the Takeda Science Foundation.

\section{References}

1. Jemal A, Siegel R, Xu J and Ward E: Cancer statistics, 2010. CA Cancer J Clin 60: 277-300, 2010.

2. Nakao A, Fujii T, Sugimoto H, Kanazumi N, Nomoto S, Kodera Y, Inoue $S$ and Takeda $S$ : Oncological problems in pancreatic cancer surgery. World J Gastroenterol 12: 4466-4472, 2006.

3. Matsuno S, Egawa S, Fukuyama S, Motoi F, Sunamura M, Isaji S Imaizumi T, Okada S, Kato H, Suda K, et al: Pancreatic cancer registry in Japan: 20 years of experience. Pancreas 28: 219-230, 2004.

4. Carpelan-Holmström M, Nordling S, Pukkala E, Sankila R, Lüttges J, Klöppel G and Haglund C: Does anyone survive pancreatic ductal adenocarcinoma? A nationwide study re-evaluating the data of the finnish cancer registry. Gut 54: 385-387, 2005.

5. Wagner M, Redaelli C, Lietz M, Seiler CA, Friess H and Büchler MW: Curative resection is the single most important factor determining outcome in patients with pancreatic adenocarcinoma. Br J Surg 91: 586-594, 2004.

6. Neoptolemos JP, Stocken DD, Friess H, Bassi C, Dunn JA, Hickey H, Beger H, Fernandez-Cruz L, Dervenis C, Lacaine $\mathrm{F}$, et al: A randomized trial of chemoradiotherapy and chemotherapy after resection of pancreatic cancer. N Engl J Med 350: 1200-1210, 2004

7. Neoptolemos JP, Stocken DD, Bassi C, Ghaneh P, Cunningham D, Goldstein D, Padbury R, Moore MJ, Gallinger S, Mariette $\mathrm{C}$, et al: Adjuvant chemotherapy with fluorouracil plus folinic acid vs. gemcitabine following pancreatic cancer resection: A randomized controlled trial. JAMA 304: 1073-1081, 2010.

8. Oettle H, Post S, Neuhaus P, Gellert K, Langrehr J, Ridwelski K, Schramm H, Fahlke J, Zuelke C, Burkart C, et al: Adjuvant chemotherapy with gemcitabine vs observation in patients undergoing curative-intent resection of pancreatic cancer: A randomized controlled trial. JAMA 297: 267-277, 2007.

9. Kwon WS, Rha SY, Choi YH, Lee JO, Park KH, Jung JJ, Kim TS, Jeung HC and Chung HC: Ribonucleotide reductase M1 (RRM1) 2464G $>$ A polymorphism shows an association with gemcitabine chemosensitivity in cancer cell lines. Pharmacogenet Genomics 16: 429-438, 2006.

10. Jordheim LP, Sève P, Trédan O and Dumontet C: The ribonucleotide reductase large subunit (RRM1) as a predictive factor in patients with cancer. Lancet Oncol 12: 693-702, 2011.

11. Nakahira S, Nakamori S, Tsujie M, Takahashi Y, Okami J, Yoshioka S, Yamasaki M, Marubashi S, Takemasa I, Miyamoto A, et al: Involvement of ribonucleotide reductase M1 subunit overexpression in gemcitabine resistance of human pancreatic cancer. Int J Cancer 120: 1355-1363, 2007.

12. Rosell R, Felip E, Taron M, Majo J, Mendez P, Sanchez-Ronco M, Queralt C, Sanchez JJ and Maestre J: Gene expression as a predictive marker of outcome in stage IIB-IIIA-IIIB non-small cell lung cancer after induction gemcitabine-based chemotherapy followed by resectional surgery. Clin Cancer Res 10: 4215s-4219s, 2004. 
13. Kim R, Tan A, Lai KK, Jiang J, Wang Y, Rybicki LA and Liu X: Prognostic roles of human equilibrative transporter 1 (hENT-1) and ribonucleoside reductase subunit M1 (RRM1) in resected pancreatic cancer. Cancer 117: 3126-3134, 2011.

14. Nakagawa N, Murakami Y, Uemura K, Sudo T, Hashimoto Y, Kondo N and Sueda T: Combined analysis of intratumoral human equilibrative nucleoside transporter 1 (hENT1) and ribonucleotide reductase regulatory subunit M1 (RRM1) expression is a powerful predictor of survival in patients with pancreatic carcinoma treated with adjuvant gemcitabine-based chemotherapy after operative resection. Surgery 153: 565-575, 2013.

15. Sobin LH and Wittekind CH (eds): TNM Classification of Malignant Tumors. 6th edition. John Wiley \& Sons, New York, NY, 2002.

16. Büchler MW, Friess H, Wagner M, Kulli C, Wagener V and Z'Graggen K: Pancreatic fistula after pancreatic head resection. Br J Surg 87: 883-889, 2000.

17. Wagner M, Z'graggen K, Vagianos CE, Redaelli CA, Holzinger F, Sadowski C, Kulli C, Zimmermann H, Baer HU and Büchler MW: Pylorus-preserving total pancreatectomy. Early and late results. Dig Surg 18: 188-195, 2001.

18. Andrén-Sandberg A, Wagner M, Tihanyi T, Löfgren P and Friess H: Technical aspects of left-sided pancreatic surgery for cancer. Dig Surg 16: 305-312, 1999

19. Seiler CA, Wagner M, Sadowski C, Kulli C and Büchler MW: Randomized prospective trial of pylorus-preserving vs. Classic duodenopancreatectomy (Whipple procedure): Initial clinical results. J Gastrointest Surg 4: 443-452, 2000

20. Valsecchi ME, Holdbrook T, Leiby BE, Pequignot E, Littman SJ, Yeo CJ, Brody JR and Witkiewicz AK: Is there a role for the quantification of RRM1 and ERCC1 expression in pancreatic ductal adenocarcinoma? BMC Cancer 12: 104, 2012.

21. Maréchal R, Bachet JB, Mackey JR, Dalban C, Demetter P, Graham K, Couvelard A, Svrcek M, Bardier-Dupas A, Hammel P, et al: Levels of gemcitabine transport and metabolism proteins predict survival times of patients treated with gemcitabine for pancreatic adenocarcinoma. Gastroenterology 143: 664-674.e1-e6, 2012.

22. Xie H, Jiang W, Jiang J, Wang Y, Kim R, Liu X and Liu X: Predictive and prognostic roles of ribonucleotide reductase M1 in resectable pancreatic adenocarcinoma. Cancer 119: 173-181, 2013.
23. Akita H, Zheng Z, Takeda Y, Kim C, Kittaka N, Kobayashi S, Marubashi S, Takemasa I, Nagano H, Dono K, et al: Significance of RRM1 and ERCC1 expression in resectable pancreatic adenocarcinoma. Oncogene 28: 2903-2909, 2009.

24. Elledge SJ, Zhou Z and Allen JB: Ribonucleotide reductase: Regulation, regulation, regulation. Trends Biochem Sci 17: 119-123, 1992.

25. Reichard P: From RNA to DNA, why so many Ribonucleotide reductases? Science 260: 1773-1777, 1993.

26. Giovannetti E, Mey V, Nannizzi S, Pasqualetti G, Del Tacca M and Danesi R: Pharmacogenetics of anticancer drug sensitivity in pancreatic cancer. Mol Cancer Ther 5: 1387-1395, 2006.

27. Povoski SP, Karpeh MS Jr, Conlon KC, Blumgart LH and Brennan MF: Association of preoperative biliary drainage with postoperative outcome following pancreaticoduodenectomy. Ann Surg 230: 131-142, 1999.

28. Yeo CJ, Cameron JL, Lillemoe KD, Sohn TA, Campbell KA, Sauter PK, Coleman J, Abrams RA and Hruban RH: Pancreaticoduodenectomy with or without distal gastrectomy and extended retroperitoneal lymphadenectomy for periampullary adenocarcinoma, part 2: Randomized controlled trial evaluating survival, morbidity, and mortality. Ann Surg 236: 355-368, 2002.

29. Kawai M, Tani M, Terasawa H, Ina S, Hirono S, Nishioka R, Miyazawa M, Uchiyama K and Yamaue H: Early removal of prophylactic drains reduces the risk of intra-abdominal infections in patients with pancreatic head resection: Prospective study for 104 consecutive patients. Ann Surg 244: 1-7, 2006.

30. Munoz-Bongrand N, Sauvanet A, Denys A, Sibert A, Vilgrain V and Belghiti J: Conservative management of pancreatic fistula after pancreaticoduodenectomy with pancreaticogastrostomy. J Am Coll Surg 199: 198-203, 2004.

31. Tran KT, Smeenk HG, van Eijck CH, Kazemier G, Hop WC, Greve JW, Terpstra OT, Zijlstra JA, Klinkert P and Jeekel H: Pylorus preserving pancreaticoduodenectomy versus standard Whipple procedure: A prospective, randomized, multicenter analysis of 170 patients with pancreatic and periampullary tumors. Ann Surg 240: 738-745, 2004. 